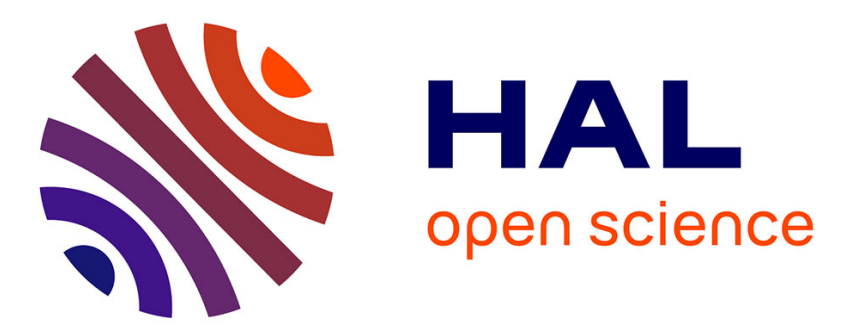

\title{
Dual lidar observations of mesoscale fluctuations of ozone and horizontal winds
}

D. E. Gibson-Wilde, R. A. Vincent, Claude Souprayen, Sophie Godin, Albert Hertzog, S. D. Eckermann

\section{- To cite this version:}

D. E. Gibson-Wilde, R. A. Vincent, Claude Souprayen, Sophie Godin, Albert Hertzog, et al.. Dual lidar observations of mesoscale fluctuations of ozone and horizontal winds. Geophysical Research Letters, 1997, 24 (13), pp.1627-1630. 10.1029/97GL01609 . insu-03087746

\section{HAL Id: insu-03087746 https://hal-insu.archives-ouvertes.fr/insu-03087746}

Submitted on 24 Dec 2020

HAL is a multi-disciplinary open access archive for the deposit and dissemination of scientific research documents, whether they are published or not. The documents may come from teaching and research institutions in France or abroad, or from public or private research centers.
L'archive ouverte pluridisciplinaire HAL, est destinée au dépôt et à la diffusion de documents scientifiques de niveau recherche, publiés ou non, émanant des établissements d'enseignement et de recherche français ou étrangers, des laboratoires publics ou privés. 


\title{
Dual lidar observations of mesoscale fluctuations of ozone and horizontal winds
}

\author{
D. E. Gibson-Wilde and R. A. Vincent \\ Department of Physics and Mathematical Physics, University of Adelaide, S.A. 5005, Australia
}

C. Souprayen, S. Godin, and A. Hertzog

Service d'Aeronomie, CNRS, France

\author{
S. D. Eckermann ${ }^{1}$ \\ Computational Physics, Inc., Fairfax, Virginia 22031
}

\begin{abstract}
A case study is presented of $6.5 \mathrm{~h}$ of simultaneous colocated stratospheric Differential Absorption Lidar (DIAL) measurements of ozone concentration and RayleighMie Doppler (RD) lidar measurements of horizontal wind velocity from the Observatoire de Haute Provence (OHP), France $\left(44^{\circ} \mathrm{N}, 6^{\circ} \mathrm{E}\right)$. The RD lidar observations reveal a distinct gravity wave motion at $\sim 12-18 \mathrm{~km}$, while the DIAL data show laminated ozone structures in the same height range. We combine these data to show that advection due to the gravity wave cannot produce the large ozone lamina at $\sim 14 \mathrm{~km}$.
\end{abstract}

\section{Introduction}

Stratospheric ozone abundances exhibit appreciable mesoscale variability. Large perturbations with vertical scales $\sim 1-5 \mathrm{~km}$ are observed routinely in ozonesonde data [Ehhalt et al., 1983; Hofmann et al., 1989; Reid and Vaughan, 1991; Teitelbaum et al., 1994; Mitchell et al., 1996], while measurements from stratospheric aircraft show variability over a broad range of horizontal scales [Nastrom et al., 1986; Danielsen et al., 1991; Bacmeister et al., 1996]. Since ozone in the lower stratosphere (below $\sim 25 \mathrm{~km}$ ) is photochemically inactive on timescales up to 5 days (in the absence of heterogeneous processing), then such variability must in general have a dynamical origin.

Gravity-wave-induced vertical advection was first suggested as a possible cause of ozone perturbations by Chiu and Ching [1978]. Aircraft observations during the StratosphereTroposphere Exchange Project (STEP) revealed inertia-gravity waves (IGWs) and seemingly related perturbations of ozone and other constituents [Chan et al., 1991; Wilson et al., 1991; Alexander and Pfister, 1995]. Danielsen et al. [1991] argued that the vertical and horizontal displacements of these IGWs produced the observed ozone perturbations, and that irreversible constituent transport resulted as these waves dissipated. Teitelbaum et al. [1994], Alexander and Pfister [1995] and Teitelbaum et al. [1996] argued that gravity-waveinduced vertical advection accounted for the ozone fluctuations in their data.

\footnotetext{
${ }^{1}$ also c/o E. O. Hulburt Center for Space Research, Code 7641, Naval Research Laboratory, Washington, D.C. 20375

Copyright 1997 by the American Geophysical Union.

Paper number 97GL01609.

0094-8534/97/97GL-01609\$05.00
}

Conversely, Ehhalt et al. [1983] found that long-term variances of ozone inferred from ozonesonde releases at Hohenpeissenberg $\left(47^{\circ} \mathrm{N}, 11^{\circ} \mathrm{E}\right)$ were significantly larger than those expected on the basis of wave-induced potential temperature fluctuations alone, indicating that gravity wave vertical advection cannot explain all of the structure. Later analysis of variability in a large base of ozonesonde data from middle to high northern latitudes by Reid et al. [1993] identified the largest perturbations (so-called "laminae") with differential transport across the polar vortex edge. High-resolution parcel advection models of this transport have succeeded in simulating laminated vertical ozone profiles which are similar to those observed [e.g., Orsolini et al., 1995]. Indeed, Newman and Schoeberl [1995] recently used such a model to argue that quasi-horizontal flow in and out of the polar vortex could explain those laminar ozone structures observed in STEP data which Danielsen et al. [1991] had previously attributed to IGW motions. Recent analysis of a large amount of airborne stratospheric ozone data by Bacmeister et al. [1996] concluded that neither IGWs nor large-scale advection alone could explain the mean mesoscale variability evident in these data, and that both effects may combine and interact to produce the observed variability.

Recent studies by Reid et al. [1994] and Langford et al. [1996] combined velocity and ozone data to investigate IGW activity in ozone. However the poor temporal resolution of sonde data was a limiting factor in the study of Reid et al. [1994] and the spatial separation of $75 \mathrm{~km}$ of the radar and DIAL instrument in the experiments of Langford et al. [1996] meant that waves observed in one data set may not always relate to those in the other. Here, we report on a pilot experiment which was devised to avoid many of these difficulties. Two colocated lidar instruments were used to acquire simultaneous stratospheric velocity and ozone data with high vertical and temporal resolution. We use these velocity data to identify and characterize an IGW in the stratosphere and to predict its effect on ozone profiles, then compare these predictions with the contemporaneous ozone data to infer the processes responsible for the structure in the ozone data.

\section{Observations}

The DIAL ozone and RD lidars, located approximately $10 \mathrm{~m}$ apart within the same building at OHP, were run simultaneously during the observation period (2230 LT on 23 October to 0500 LT on 24 October, 1995). Table 1 sum- 
Table 1. DIAL and RD lidar capabilities at OHP.

\begin{tabular}{|c|c|c|}
\hline & Ozone DIAL & RD lidar \\
\hline $\begin{array}{l}\text { Beam } \\
\text { direction }\end{array}$ & vertical & $\begin{array}{l}\text { vertical + off-zenith } \\
40^{\circ} \text { north and east }\end{array}$ \\
\hline Wavelengths & $\begin{array}{l}\text { absorbed } 308 \mathrm{~nm} \\
\text { reference } 355 \mathrm{~nm}\end{array}$ & $532 \mathrm{~nm}$ \\
\hline PRF & $50 \mathrm{~Hz}$ & $30 \mathrm{~Hz}$ \\
\hline Height resol. & $600 \mathrm{~m}$ & $115 \mathrm{~m}$ \\
\hline Time resol. & $30 \mathrm{~min}$ & $30 \mathrm{~min}$ \\
\hline Height range & $12-30 \mathrm{~km}$ & $12-45 \mathrm{~km}$ \\
\hline $\begin{array}{l}\text { Major error } \\
\text { sources }\end{array}$ & $\begin{array}{l}\text { water vapour } \\
\text { aerosols }\end{array}$ & aerosols \\
\hline
\end{tabular}

marizes the operational specifics of both lidar systems (see also Garnier and Chanin [1992] and Lacoste et al. [1992]). Measurements of lower stratospheric $(12-30 \mathrm{~km})$ ozone concentration were provided by the DIAL system and zonal and meridional velocities were provided by the RD lidar.

Figure 1 presents the sequence of DIAL ozone concentration profiles in two consecutive plots. The estimated error in measurement is $\sim 10 \%$ in the height range $12-20 \mathrm{~km}$. The RD lidar zonal and meridional velocity profiles in Figure 2 are displayed at a vertical grid spacing of $150 \mathrm{~m}$, obtained from regridding using spline interpolation from the initial $115 \mathrm{~m}$ resolution, for compatibility with the DIAL profiles. The RD lidar data are acquired typically with a time resolution of $5 \mathrm{~min}$ so that the $30 \mathrm{~min}$ profiles presented here have an estimated error of less than $5 \%$ between $12-20 \mathrm{~km}$.

Figure 3 displays the average ozone concentration profile calculated over the $6.5 \mathrm{~h}$ observation period. The error associated with this average profile is $\sim 2 \%$ in the height range $12-20 \mathrm{~km}$. The small-scale features evident in this average profile must result from dynamical activity on timescales greater than 6.5 hours.

\section{Ozone Laminae}

The two local maxima in ozone concentration in Figure 3 at $\sim 14 \mathrm{~km}$ and $\sim 18 \mathrm{~km}$ are examples of ozone laminae. They were identified as such using the definition of Reid and Vaughan [1991] which requires large positive or negative ozone concentrations which are limited to a layer less than
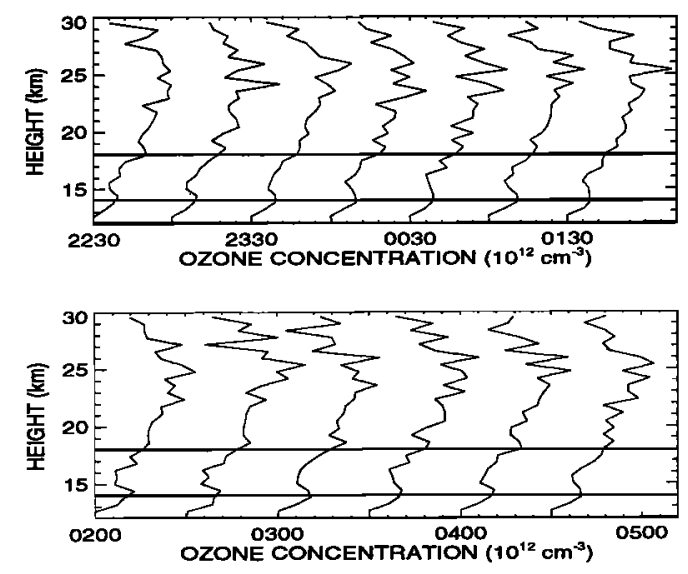

Figure 1. DIAL ozone concentration profiles from 2230 LT on 23 October to 0500 LT on 24 October, 1995. Each profile is labeled by the start time of its $\mathbf{3 0} \mathrm{min}$ integration. Successive profiles are offset by $5 \times 10^{12} \mathrm{~cm}^{-3}$.
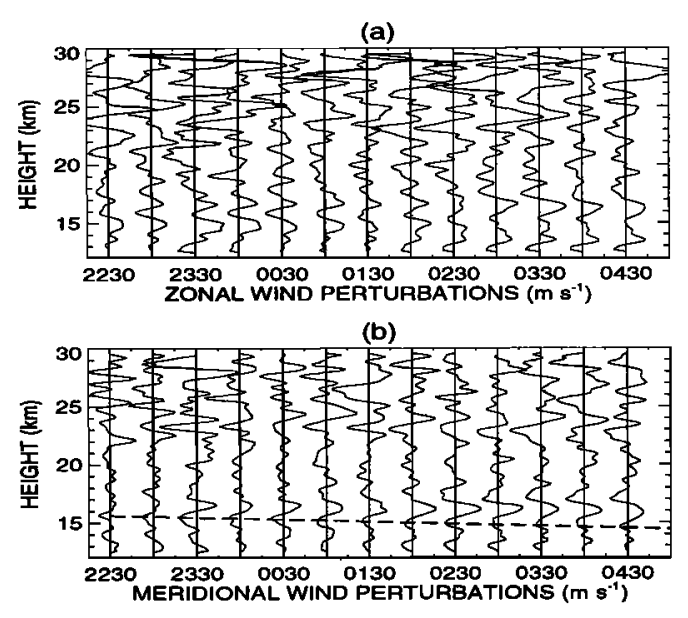

Figure 2. RD lidar profiles from $2230 \mathrm{LT}$ on 23 October to 0500 LT on 24 October, 1995. The zero point of each profile is labeled with the starting time of its $30 \mathrm{~min}$ observational integration. Successive profiles are offset by $10 \mathrm{~m} \mathrm{~s}^{-1}$.

$2.5 \mathrm{~km}$ in vertical extent. Reid and Vaughan [1991] found that the majority of laminae in mid-latitude, northern hemispheric ozonesonde data were within the height range $12-18 \mathrm{~km}$.

The $6.5 \mathrm{~h}$ mean lidar ozone concentration profile (Figure 3) was compared with an ozone concentration profile from an ozonesonde launched from OHP at 1200 LT on 24 October $1995,7 \mathrm{~h}$ after the final lidar profile (not shown here). The ozonesonde profile confirmed the lidar observation of the lamina at $14 \mathrm{~km}$ so that a minimum lifetime of $14 \mathrm{~h}$ was estimated for the lamina at $14 \mathrm{~km}$ based on its occurrence in both the lidar and ozonesonde profiles. The lamina at $18 \mathrm{~km}$ was reduced by the time of the ozonesonde flight. Thus, from the lidar observations alone, the estimated minimum lifetime for the $18 \mathrm{~km}$ lamina was $6.5 \mathrm{~h}$.

\section{An Inertia Gravity Wave}

Successive vertical profiles of zonal and meridional velocities from the RD lidar (Figure 2) indicate a wave-like feature below $20 \mathrm{~km}$ with downward phase (upward energy) propagation which persists throughout the $6.5 \mathrm{~h}$ observation period. A hodograph analysis (Figure 4) shows mostly clockwise rotation of the velocity fluctuations with height and a well-defined velocity ellipse, which suggests that this feature is a long-period upward-propagating IGW. The wave parameters were derived from these data using a Stokes parameter analysis [e.g., Eckermann, 1996] and are presented in Table 2 . The values of observed and intrinsic wave frequency were used to infer that the horizontal propagation direction of the IGW was towards the south-west.

\section{Vertical IGW Displacements}

The IGW parameters in Table 2 were used to estimate the influence of vertical advection due to this IGW on the ozone concentration profile. For adiabatic motion and a constant background ozone gradient, the relative ozone concentration perturbation, $O_{3}^{\prime} / O_{3}$, is given by [Chiu and Ching, 1978]

$$
\frac{O_{3}^{\prime}(z, t)}{\bar{O}_{3}(z)} \approx\left(\frac{-\zeta^{\prime}(z, t)}{\bar{O}_{3}(z)}\right)\left(\frac{d \bar{O}_{3}(z)}{d z}+\frac{\bar{O}_{3}(z)}{\gamma H}\right)
$$




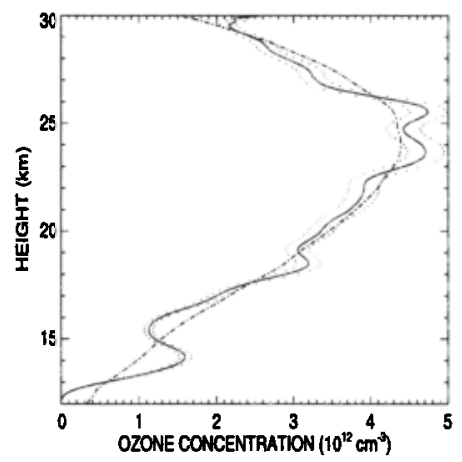

Figure 3. Mean $6.5 \mathrm{~h}$ profile of ozone concentration (bold line) and fitted mean profile (dashed-dotted line). A 5\% error estimate is indicated by the dotted line.

where

$$
\zeta^{\prime}(z, t) \approx \frac{i U^{\prime}(z, t)}{N} \delta_{-}^{1 / 2}(\hat{\omega})
$$

is the vertical displacement of a parcel by the IGW, $\hat{\omega}$ is intrinsic frequency, $\delta_{-}(\hat{\omega})=1-(f / \hat{\omega})^{2}, f$ is the inertial frequency, $U^{\prime}(z, t)$ is the horizontal velocity perturbation along the wave vector, $\bar{O}_{3}(z)$ is the background ozone concentration (assumed time-invariant), $H$ is the pressure scale height, $\gamma$ is the ratio of specific heats $(\sim 1.4)$, and $N$ is the BruntVäisälä frequency $\left(\sim 0.02 \mathrm{rad} \mathrm{s}^{-1}\right.$ based on ozonesonde temperature data). The $\bar{O}_{3}(z)$ profile was estimated by a lowpass filtered cubic polynomial fit to the mean profile, which removes the laminae (see Figure 3).

Figure 5a shows the measured $O_{3}^{\prime}(z, t) / \bar{O}_{3}(z)$ deviations from the cubic polynomial-fitted profile, as well as the expected perturbation produced by the IGW in Figure 4, calculated by first converting $U^{\prime}(z, t)$ to a $\zeta^{\prime}(z, t)$ oscillation using (2) (see Figure $5 \mathrm{~b}$ ), then using this to calculate $O_{3}^{\prime}(z, t) / O_{3}(z)$ using $(1)$. The relative magnitudes of the measured and calculated ozone perturbations in Figure 5a show that the vertical advection produced by the IGW in Figure 4 can drive only a 5\% relative ozone fluctuation, except in the height region below $\sim 14.5 \mathrm{~km}$ where the inverse dependence on $\bar{O}_{3}(z)$ in (1) leads to perturbations of up to $10 \%$. The estimation of $\bar{O}_{3}(z)$ using the smoothed profile with laminae removed is the key factor in this calculation,

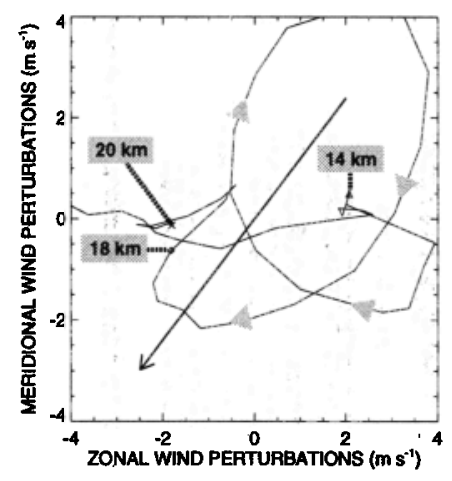

Figure 4. Hodograph between $12-20 \mathrm{~km}$ of mean $6.5 \mathrm{~h} \mathrm{zonal}$ and meridional wind fluctuations smoothed over $600 \mathrm{~m}$. The bold line is the major axis of the gravity-wave ellipse from the Stokes parameters analysis.
Table 2. IGW parameters derived from successive RD lidar profiles and Stokes parameters analysis.

\begin{tabular}{ll}
\hline Wave Parameter & Estimated Value \\
\hline Vertical wavelength & $2.3 \mathrm{~km}$ \\
Observed vertical phase speed & $-0.06 \mathrm{~m} \mathrm{~s}^{-1}$ \\
Observed frequency & $1.6 f \sim 0.00016 \mathrm{rad} \mathrm{s}^{-1}$ \\
Intrinsic frequency & $2.2 f \sim 0.00022 \mathrm{rad} \mathrm{s}^{-1}$ \\
Horizontal wavelength & $360 \mathrm{~km}$ \\
\hline
\end{tabular}

and gives the expected response in the absence of preexisting ozone lamination. Figure 5 clearly illustrates that the lamina at $14 \mathrm{~km}$ cannot result from vertical advection by the coexisting IGW in Figure 4.

\section{Horizontal IGW Displacements}

Horizontal IGW displacements were neglected in (1) because the lidar data do not provide information on mean horizontal gradients in $\overline{O_{3}}$. However, when zonal and meridional $\bar{O}_{3}$ gradients are nonzero, additional contributions to (1) arise due to the zonal $\left(\chi^{\prime}\right)$ and meridional $\left(\psi^{\prime}\right)$ displacements of the wave [e.g., Danielsen et al., 1991]. Since the IGW propagates south westward, with $\hat{\omega} \approx 2.2 f$ and $U^{\prime}$ peaking at $\sim 4 \mathrm{~m} \mathrm{~s}^{-1}$, then $\chi^{\prime}$ and $\psi^{\prime}$ both oscillate air parcels $\pm 12.7 \mathrm{~km}$ zonally and meridionally from their equilibrium positions.

For horizontal IGW displacements to produce the lamina at $14 \mathrm{~km}$, large increases in $\bar{O}_{3}$ must occur no more than $\sim 20 \mathrm{~km}$ away from the lidar site so that the IGW can advect these larger ozone abundances into (and then out of) the lidar field-of-view. This also means that such an IGW-produced lamina could exist over a given location for no longer than one ground-based period of the wave, which from Table 2 is $\sim 10.8 \mathrm{~h}$. Since the lamina at $14 \mathrm{~km}$ was observed to be stable over at least $14 \mathrm{~h}$, it is clear that horizontal advection due to the IGW cannot explain this feature.

Since advection by the IGW cannot produce the observed lamina at $14 \mathrm{~km}$, this strongly suggests that it resulted from synoptic-scale advection patterns. Initial indications from isentropic parcel advection calculations suggest that a filamentary structure was indeed present at approximately $14 \mathrm{~km}$ over OHP during this experiment [R.J. Atkinson, private communication]. The lamina at $18 \mathrm{~km}$ appeared to vary in shape and intensity from profile to profile (see Figure 1). Consequently, IGW-induced horizontal advection could play a more significant role in driving this feature.

\section{Conclusions}

The dual lidar measurement technique described here permits a more thorough study of mesoscale dynamics and tracer variability than has been possible previously. The RD lidar data revealed an upward-propagating IGW below $20 \mathrm{~km}$, with a vertical wavelength of $2.3 \mathrm{~km}$, an observed vertical phase speed $\sim 0.06 \mathrm{~m} \mathrm{~s}^{-1}$, and a peak horizontal velocity amplitude of $\sim 4 \mathrm{~m} \mathrm{~s}^{-1}$. We were able to show conclusively that the strength and persistence of an ozone lamina at $14 \mathrm{~km}$ in DIAL data was not explained by wave advection. Conversely, the observed variability of a lamina at $18 \mathrm{~km}$ was somewhat more consistent with IGW influences.

The time-height coverage and resolution of both data sets were vital in allowing us to form these conclusions. Further observations using this technique should be especially valuable in investigating gravity waves, filamentary ozone structures, and their interactions, which Bacmeister et al. [1996] 
(a)

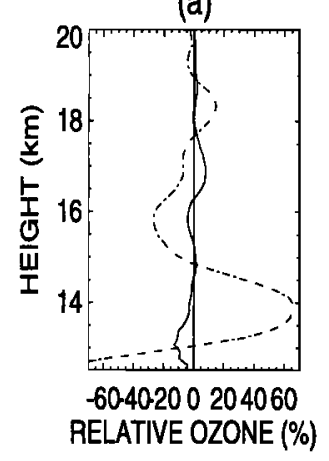

(b)

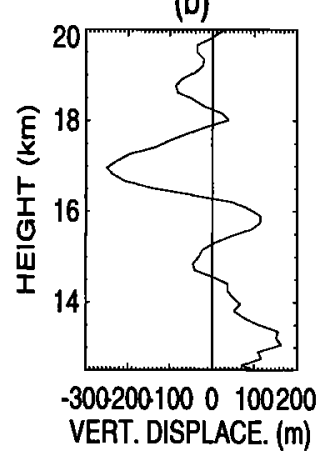

Figure 5. Measured relative ozone concentration perturbation determined by subtracting a cubic polynomial mean profile (dotted-dashed curve in panel (a)) and calculated response of the IGW using (1) and (2) (solid curve in panels (a) and (b), respectively).

have argued may be very important in explaining observed power spectra of ozone variability in the lower stratosphere.

Acknowledgments. We thank the OHP staff and Dr. R. Atkinson of BMRC, Melbourne, for useful comments. DGW acknowledges University of Adelaide support to visit CNRS.

\section{References}

Alexander, M. J., and L. Pfister, Gravity wave momentum flux in the lower stratosphere over convection, Geophys. Res. Lett., 22, 2029-2032, 1995.

Bacmeister, J. T., S. D. Eckermann, P. A. Newman, L. Lait, K. R. Chan, M. Loewenstein, M. H. Profitt, and B. L. Gary, Stratospheric horizontal wavenumber spectra of winds, potential temperature and atmospheric tracers observed by high-altitude aircraft, J. Geophys. Res., 101, 9441-9470, 1996.

Chan, K. R., S. G. Scott, S. W. Bowen, S. E. Gaines, E. F. Danielsen, and L. Pfister, Horizontal wind fluctuations in the stratosphere by internal waves of short vertical wavelength, $J$. Geophys. Res., 96, 17,425-17,432, 1991.

Chiu, Y. T., and B. K. Ching, The response of atmospheric and lower ionospheric layer structures to gravity waves, Geophys. Res. Lett., 5, 539-542, 1978.

Danielsen, E. F., R. S. Hipskind, W. L. Starr, J. F. Vedder, S. E. Gaines, D. Kley, and K. K. Kelly, Irreversible transport in the stratosphere by internal waves of short vertical wavelength, $J$. Geophys. Res., 96, 17,433-17,452, 1991.

Eckermann, S. D., Hodographic analysis of gravity waves: Relationships among Stokes parameters, rotary spectra, and crossspectral methods, J. Geophys. Res., 101, 19,169-19,174, 1996.

L-1halt, D. G., E. P. Roth, and U. Schmidt, On the temporal variance of stratospheric gas concentrations, J. Atmos. Chem., 1,27$51,1983$.

Garnier, A., and M. L. Chanin, Description of a Doppler Rayleigh LIDAR for measuring winds in the middle atmosphere, $A p p$. Phys. B, 55, 35-40, 1992.

Hofmann, D. J., J. W. Harder, J. M. Rosen, J. V. Hereford, and J. R. Carpenter, Ozone profile measurements at McMurdo Station, Antarctica, during the spring of 1987, J. Geophys. Res., 94, 16,527-16,536, 1989.

Lacoste, A. M., S. Godin, and G. Megie, Lidar measurements and Umkehr observations of the ozone vertical distribution at the Observatoire de Haute Provence, J. Atmos. Terr. Phys., 54, 571$580,1992$.

Langford, A. O., M. H. Proffitt, T. E. VanZandt, and J.-F. Lamarque, Modulation of tropospheric ozone by a propagating gravity wave, J. Geophys. Res., 101, 26,605-26,613,1996.

Mitchell, N. J., A. J. McDonald, S. J. Reid, and J. D. Price, Observations of gravity waves in the upper and lower stratosphere by lidar and ozonesondes, Ann. Geophys., 14, 309-314, 1996.

Nastrom, G. D., W. H. Jasperson, and K. S. Gage, Horizontal spectra of atmospheric tracers measured during the Global Atmospheric Sampling Campaign, J. Geophys. Res., 91, 13,201$13,209,1986$.

Newman, P. A., and M. R. Schoeberl, A reinterpretation of the data from the NASA Stratosphere-Troposphere Exchange Project, Geophys. Res. Lett., 22, 2501-2504, 1995.

Orsolini, Y., P. Simon, and D. Cariolle, Filamentation and layering of an idealized tracer by observed winds in the lower stratosphere, Geophys. Res. Lett., 22, 839-842, 1995.

Reid, S. J., and G. Vaughan, Lamination in ozone profiles in the lower stratosphere, Q. J. R. Meteorol. Soc., 117, 825-844, 1991.

Reid, S. J., G. Vaughan, and E. Kyro, Occurrence of ozone laminae near the boundary of the stratospheric polar vortex, J. Geophys. Res., 98, 8883-8890, 1993.

Reid, S. J., G. Vaughan, N. J. Mitchell, I. T. Prichard, H. J. Smit, T. S. Jorgensen, $C$. Varotsos, and $H$. de Backer, Distribution of ozone laminae during EASOE and the possible influence of inertiagravity waves, Geophys. Res. Lett., 21, 1479-1482, 1994.

Teitelbaum, H., J. Ovarlez, H. Kelder, and F. Lott, Some observations of gravity-wave-induced structure in ozone and water vapour during EASOE, Geophys. Res. Lett., 21, 14831486, 1994.

Teitelbaum, H., M. Moustaoui, J. Ovarlez, and H. Kelder, The role of atmospheric waves in the laminated structure of ozone profiles at high latitudes, Tellus, 48A, 422-455, 1996.

Wilson, J. C., W. T. Lai, and S. D. Smith, Measurements of condensation nuclei above the jet stream: Evidence for cross jet transport by waves and new particle formation at high altitudes, $J$. Geophys. Res., 96, 17,415-17,423, 1991.

Dorothy Gibson-Wilde and Robert Vincent, Department of Physics and Mathematical Physics, University of Adelaide, 5005, Australia. (e-mail: dgibson@physics.adelaide.edu.au)

Claude Souprayen, Sophie Godin, and Albert Hertzog, Service d'Aeronomie, CNRS, France.

Stephen Eckermann, Computational Physics, Inc., Fairfax, Virginia. (e-mail: eckerman@darwin.cpi.com)

(Received January 28, 1997; accepted March 26, 1997.) 